УДК 342.95:61(045)

\title{
А.А. Мухин
}

\section{ПРОГНОЗИРОВАНИЕ ЗНАЧЕНИЙ ФАКТОРОВ ЭКОНОМИЧЕСКОГО РОСТА РЕГИОНА НА ПРИМЕРЕ УДМУРТСКОЙ РЕСПУБЛИКИ}

Рассматривается прогнозирование значений факторов экономического роста региона на примере Удмуртской Республики. Построено статистически значимое уравнение множественной линейной регрессии, объясняющей динамику валового регионального продукта от признаков-факторов, разработан прогноз и интерпретированы полученные результаты. Для элиминирования влияния роста цен применен метод дефлятирования, и произведен расчет стоимости ВРП в ценах 2007 г. На основе множественного регрессионного анализа рассчитывается матрица парных коэффициентов корреляции и производится отбор информативных факторов модели. Проверяется значимость парных коэффициентов корреляции. Строится модель в естественной форме только с информативными факторами. Проведена оценка статистической значимости коэффициентов регрессии с помощью t-критерия Стьюдента, качества уравнения через среднюю ошибку аппроксимации, которые подтверждают достаточно высокое качество модели. Рассчитывается прогнозное значение результата. Выявлено, что при сохранении сложившихся тенденций динамики указанных факторов можно ожидать рост реального (физического объема) ВРП за период 2016-2020 гг. на 26 \% или на 5,5 \% ежегодно, что соответствует требованиям экономической безопасности региона. Указанная информация может быть использована для разработки программ регионального экономического развития и проектирования в системе государственного и муниципального управления.

Ключевые слова: прогнозирование значений факторов экономического роста региона, эндогенные, экзогенные переменные, корреляционный, регрессионный анализ факторов, оценка качества регрессионного уравнения с помощью F-критерия Фишера, значимость коэффициентов регрессии с помощью t-критерия Стьюдента, качество уравнения через среднюю ошибку аппроксимации. Расчет прогнозного значения экономического роста Удмуртской Республики.

DOI: $10.35634 / 2412-9593-2020-30-1-78-83$

Цель статьи - построение статистически значимого уравнения множественной линейной регрессии, объясняющей динамику валового регионального продукта от признаков-факторов, разработка прогноза и интерпретация полученных результатов.

Развитие экономических процессов или объектов описывается количественными характеристиками, которые формируются под действием множества факторов, не все из которых доступны внешнему контролю [1]. Но современный экономико-математический аппарат позволяет выявить наиболее значимые факторы.

Основным показателем экономического роста региона является валовой региональный продукт (ВРП). В Удмуртии ВРП в целом имеет положительную динамику с 205,6 млрд руб. в 2007 г. до 540 млрд руб. в 2016 г., рост в 2,63 раза. Указанные величины отражают учтенные экономические операции текущих рыночных цен (которые в условиях инфляции неизбежно растут). Для элиминирования влияния роста цен применим метод дефлятирования и произведем расчет стоимости ВРП в ценах 2007 г. (табл. 1) [2-4]. Физический реальный объем ВРП Удмуртии за период 2007-2016 г. увеличился всего лишь на 15,2 \%, следовательно, ежегодный экономический рост за указанный период составлял не более $1,6 \%$. По требованиям соблюдения условий экономической безопасности региона и сохранения устойчивости его экономического развития ежегодный рост ВРП должен составлять не менее $4 \%$ ежегодно [5]. Поэтому поиск факторов оживления экономики является актуальной задачей для науки и практики, а экономико-математический анализ выступает адекватным инструментом ее решения, что неоднократно подчеркивалось и апробировано рядом ученых [6; 7].

Эндогенные переменные - валовый региональный продукт Удмуртской Республики.

Экзогенные переменные - инвестиции в основной капитал (млрд руб), число предприятий, использовавших информационные технологии (ед.), численность занятых (тыс. чел.).

Помимо традиционных показателей труда и капитала нами предложено рассмотреть использование информационных технологий. Органами статистики ведется учет масштабов распространения использования информационных и коммуникационных технологий организациями практически всех видов экономической деятельности (по кругу обследованных организаций, без субъектов малого предпринимательства). 
Социально-экономические показатели Удмуртской Республики 2007-2016 годов

\begin{tabular}{|c|c|c|c|c|}
\hline Год & $\begin{array}{c}\text { Валовый региональный } \\
\text { продукт (в ценах 2007 } \\
\text { года), млрд руб. } \\
Y\end{array}$ & $\begin{array}{c}\text { Инвестиции } \\
\text { в основной капитал, } \\
\text { млрд руб. } \\
X_{1}\end{array}$ & $\begin{array}{c}\text { Число предприятий, использо- } \\
\text { вавших информационные тех- } \\
\text { нологии, } е \text {. }\end{array}$ & $\begin{array}{c}\text { Численность } \\
\text { занятых, } \\
\text { тыс. чел. } \\
X_{2}\end{array}$ \\
\hline 2007 & 205,6 & 44,6 & 1986 & $X_{3}$ \\
2008 & 211,2 & 45 & 1924 & 766,3 \\
2009 & 198,5 & 34 & 1982 & 759,6 \\
2010 & 207,8 & 41 & 1994 & 759,2 \\
2011 & 217,8 & 49,4 & 1928 & 757,0 \\
2012 & 225,0 & 47,6 & 2070 & 755,9 \\
2013 & 231,0 & 53,9 & 2119 & 781,6 \\
2014 & 233,4 & 54,8 & 2256 & 781,0 \\
2015 & 232,9 & 44,4 & 2291 & 779,6 \\
2016 & 236,8 & 47,2 & 2462 & 764,2 \\
\hline
\end{tabular}

Методика решения (построена по традиционной для автора форме) [6]. Результатом должен явиться прогноз величины валового регионального продукта УР на 2020 г.

Факторные признаки для построения регрессионной модели ${ }^{1}$.

\section{1. Выбор факторных признаков для построения двухфакторной регрессионной модели}

Для выбора значимых показателей-факторов используем корреляционный анализ на основе матрицы парных коэффициентов корреляции между рассматриваемыми переменными.

Валовый региональный продукт - это зависимая переменная - Y (тыс. руб.).

В качестве независимых, объясняющих переменных выбраны:

Инвестиции в основной капитал $-X_{1}$. Значения данного фактора представлены с учетом цен на продукцию (затраты, услуги) инвестиционного назначения за период с 2007 по 2016 г.

Число предприятий, использовавших информационные технологии $-X_{2}$.

Численность занятых $-X_{3}$.

\section{2. Анализ матрицы коэффициентов парной корреляции}

Матрица построена с помощью Excel, она симметрична, на ее диагонали стоят единицы.

Таблица 2

\begin{tabular}{lccc}
\hline & 3начения колонки 1 & 3начения колонки 2 & Значения колонки 3 \\
\hline Значения колонки 1 & 1 & & \\
Значения колонки 2 & 0,74 & 1 & 1 \\
Значения колонки 3 & 0,82 & 0,34 & 0,44 \\
3начения колонки 4 & 0,54 & 0,52 & \\
\hline
\end{tabular}

Анализ показывает, что эндогенная переменная $Y$ «Валовый региональный продукт» имеет тесную связь с экзогенными переменными: инвестиции в основной капитал, число предприятий, использовавших информационные технологии, с численностью занятых в экономике имеется умеренная связь.

Оценка параметров регрессии осуществляется методом наименьших квадратов в матричной форме по традиционной формуле [6]:

$$
A=\left(X^{\prime} X\right)^{-1} X^{\prime} Y .
$$

Используя матричное исчисление, получим:

\footnotetext{
1 Удмуртия в цифрах. 2017 год: (стат. ежегод.): (№003 по кат.) /Федер. служба гос. статистики, Территор. орган Федер. службы гос. статистики по Удмурт. Респ.; [редкол.: Е.А. Данилов и др.]. Ижевск: Удмуртстат, 2018. 349 с.
} 


$$
\begin{array}{rr}
\left(\begin{array}{l}
a_{0} \\
a_{1} \\
a_{2}
\end{array}\right)=\left[\left(\begin{array}{cccc}
1 & 1 & \ldots & 1 \\
x_{1,1} & x_{2,1} \ldots & x_{7,1} \\
x_{1,2} & x_{2,2} \ldots & x_{7,2}
\end{array}\right)\left(\begin{array}{ccc}
1 & x_{1,1} & x_{1,2} \\
1 & x_{2,1} & x_{2,2} \\
\ldots & \ldots & \ldots \\
1 & x_{7,1} & x_{7,2}
\end{array}\right)\right]^{-1} \times\left(\begin{array}{cccc}
1 & 1 & \ldots & 1 \\
x_{1,1} & x_{2,1} \ldots & x_{7,1} \\
x_{1,2} & x_{2,2} \ldots & x_{7,2}
\end{array}\right)\left(\begin{array}{c}
y_{1} \\
y_{2} \\
\ldots \\
y_{167}
\end{array}\right), \\
\left(X^{\prime} X\right)=\left(\begin{array}{ccc}
10 & 462 & 21012 \\
462 & 21665 & 973843 \\
21012 & 973843 & 44442283
\end{array}\right) & \left(X^{\prime} X\right)^{-1}=\left(\begin{array}{ccc}
17 & -0,1 & 0,0 \\
-0,1 & 0 & 0 \\
0,0 & 0 & 0
\end{array}\right) \\
X^{\prime} Y=\left(\begin{array}{c}
2200 \\
102171 \\
4640734
\end{array}\right) & A=\left(X^{\prime} X\right)^{-1} X^{\prime} Y=\left(\begin{array}{c}
a_{0} \\
a_{1} \\
a_{2}
\end{array}\right)=\left(\begin{array}{c}
62,98 \\
1,2 \\
0,05
\end{array}\right)
\end{array}
$$

Запишем уравнение зависимости «величины валового продукта от инвестиций в основной капитал и число предприятий, использовавших информационные технологии в традиционной эконометрической форме» [1]:

$$
y=62,98+1,2 x_{1}+0,05 x_{2} .
$$

Аналогично используемым ранее методам «в протоколе выполнения регрессионного анализа с помощью Excel отображены коэффициенты уравнения регрессии $a_{0}, a_{1}, a_{2}$, стандартные ошибки коэффициентов, статистика, используемая для проверки значимости коэффициентов уравнения регрессии, индекс корреляции, критерий Фишера и другие параметры. Данные матричного исчисления и протокол уравнения регрессии совпали» [7].

\section{3. Оценка качества, точности и значимости модели}

С помощью расчета модельного значения зависимой переменной $Y$ и значения остаточной компоненты $e_{i}$ (табл. 3) рассчитаем коэффициенты.

Коэффициент детерминации:

$$
R^{2}=R_{y x_{1} x_{2}}^{2}=1-\frac{\sum_{i=1}^{n} e_{i}^{2}}{\sum_{i=1}^{n}\left(y_{1}-\bar{y}\right)^{2}}=1-\frac{138}{1675}=0,92 .
$$

Это означает, что 92 \% вариации величины валового продукта зависит от вариации изучаемых показателей-факторов.

Таблица 3

\section{Вывод остатка}

\begin{tabular}{|c|c|c|c|c|}
\hline Наблюдение & $y$ & $\hat{y}_{x}$ & $\begin{array}{c}\text { Остатки } \\
\left|y-\hat{y}_{x}\right|\end{array}$ & $\frac{\left|y-\hat{y}_{x}\right|}{y} \cdot 100$ \\
\hline 1 & 205,6 & 212,5 & 6,9 & 3,4 \\
2 & 211,2 & 210,0 & 1,2 & 0,6 \\
3 & 198,5 & 199,7 & 1,2 & 0,6 \\
4 & 207,8 & 208,6 & 0,8 & 0,4 \\
5 & 217,8 & 215,4 & 2,4 & 1,1 \\
6 & 225 & 220,2 & 4,8 & 2,1 \\
7 & 231 & 230,1 & 0,9 & 0,4 \\
8 & 233,4 & 237,8 & 4,4 & 1,9 \\
9 & 232,9 & 227,1 & 5,8 & 2,5 \\
10 & 236,8 & 238,7 & 1,9 & 0,8 \\
\hline Сумма & 2200 & 2200 & & 13,8 \\
\hline \multicolumn{5}{|c}{} \\
\hline \multicolumn{5}{|c}{} \\
\hline
\end{tabular}

Коэффициент множественной корреляции:

$$
R=\sqrt{R^{2}}=0,96 .
$$

Он показывает одновременное влияние двух факторов. Величина блика к 1 , результатам расчетов можно доверять. 
$F$-критерий Фишера отражает значимость полученной зависимости:

$$
F=\frac{R^{2} / k}{\left(1-R^{2}\right) /(n-k-1)}=\frac{0,92 / 2}{(1-0,92) /(10-2-1)}=39 .
$$

В нашем примере $F_{\text {расч. }}>F_{\text {табл. }}$, то есть $39>4,1$. Условие выполняется, значит модель рассчитана верно, ее параметрам можно доверять.

Точность модели оценим с помощью средней ошибки аппроксимации $E_{\text {отн }}$ :

$$
\begin{gathered}
\hat{y}_{x}=62,98+1,2 x_{1}+0,05 x_{2} \\
\mathrm{E}_{\text {отн }}=\frac{1}{n} \sum_{t=1}^{n} \frac{\left|e_{t}\right|}{y_{t}} \cdot 100 \%=\frac{13,8}{10}=1,38 \% .
\end{gathered}
$$

Вывод: $\mathrm{E}_{\text {отн }}=1,38 \%$ - хороший уровень точности модели.

Значения $t$-критерия Стьюдента для коэффициентов уравнения регрессии $a_{0}, a_{1}, a_{2}$ вычислим по формуле:

$$
\begin{gathered}
t_{a_{j}}=\hat{a}_{j} / s_{a_{j}}=\hat{a}_{j} /\left(S_{e} \sqrt{b_{j j}}\right)[6] \\
\left(X^{\prime} X\right)^{-1}=\left(\begin{array}{ccc}
67,7 & 0,2 & -1,4 \\
0,2 & 0,0046 & -0,01 \\
-1,4 & -0,01 & 0,03
\end{array}\right) \\
b_{11}=67,7, b_{22}=0,0046, b_{33}=0,03, \\
t_{a_{j}}=\hat{a}_{j} / S_{a_{j}}=\hat{a}_{j} /\left(S_{e} \sqrt{b_{j j}}\right), \\
t_{a_{0}}=\frac{67,7}{4,4 \sqrt{67,7}}=1,7, \\
t_{a_{1}}=\frac{1,2}{4,4 \sqrt{0,0046}}=3,9 .
\end{gathered}
$$

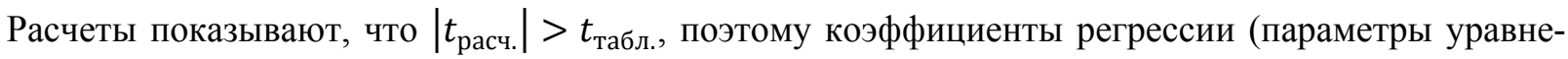
ния) $a_{1}, a_{2}, a_{3}$ существенны.

\section{4. Оценка влияние факторов на зависимую переменную по модели с помощью коэффициентов эластичности}

$$
\begin{gathered}
\exists_{j}=\hat{a}_{j} \bar{x}_{j} / \bar{y}, \\
\hat{y}_{x}=62,98+1,2 x_{1}+0,05 x_{2} . \\
\ni_{1}=\frac{1,2 \cdot 46,19}{220}=0,25, \\
\exists_{2}=\frac{0,05 \cdot 2101}{220}=0,46, \\
\beta_{j}=\hat{a}_{j} S_{x_{j}} / S_{y}, \\
\beta_{1}=1,2 \cdot 6,1 / 13,6=0,529, \\
\beta_{2}=0,05 \cdot 180,1 / 13,6=0,641 .
\end{gathered}
$$

Коэффициент эластичности Э 1 показывает влияние фактора инвестиций, увеличение которого на 1 млрд руб., приводит к увеличению ВРП на 0,25 млрд руб., а согласно второму коэффициенту $\beta_{1}$ увеличение инвестиций в основной капитал 6,1 млрд руб. приводит к росту ВРП на 7,2 млрд руб. $(0,529 \cdot 13,6=7,2$ млрд руб. $)$.

Фактор использования информационных технологий предприятиями более значимый, так как согласно значению коэффициента эластичности $Э_{2}$ увеличение этого фактора на 1 ед. ВРП увеличивается на 0,46 млрд руб., а коэффициент $\beta_{2}$ показывает, что при увеличении числа предприятий, использовавших информационные технологии на 180 ед., валовый региональный продукт увеличится на 9,5 млрд руб. $(0,641 \cdot 13,6=8,74$ млрд руб. $)$.

Прогнозные значения определим с учетом временной компоненты для разных периодов времени. 


\section{5. Построение прогноза валового регионального продукта на 2020 год}

Для фактора $X_{1}$ «Инвестиции в основной капитал, млрд руб.» выбран полином 4-й степени:

$$
X_{1}=0,0301 t^{4}-0,8546 t^{3}+7,8964 t^{2}-25,566 t+65,008 .
$$

Величина достоверности аппроксимации уравнения равна $65 \%$.

Для фактора $X_{2}$ «Число предприятий, использовавших информационные технологии, eд.» выбрана парабола:

$$
\hat{y}_{x}=9,6553 t^{2}-53,239 t+2022,3 .
$$

Величина достоверности аппроксимации уравнения равна $96 \%$.

Прогноз валового регионального продукта Удмуртской Республики на 2020 г. (в ценах 2007 г.) составит, млрд руб.:

$$
\mathrm{Y}=62,98+1,2 \cdot 66,3+0,05 \cdot 3169,4=301 \text { млрд руб. }
$$

При сохранении сложившихся тенденций динамики указанных факторов можно ожидать рост реального (физического объема) ВРП за период 2016-2020 гг. на 26 \% или на 5,5\% ежегодно, что соответствует требованиям экономической безопасности региона.

Указанные тенденции вполне достижимы, так как в фактических ценах «в 2019 году в Удмуртии ожидают роста валового регионального продукта (ВРП) в районе $10 \%$. ВРП Удмуртии по итогам 2018 г. составил 600 млрд руб., что на 43,8 млрд руб. больше значения 2017 года» [7].

Для этого следует в бюджете республики предусмотреть величину расходов на инвестирование в основной капитал с увеличением не менее на 6,1 млрд руб. ежегодно, а также разработать меры по стимулированию предприятий для использования ими современных информационных технологий (ежегодное увеличение таких предприятий должно составлять 180 ед.).

\section{СПИСОК ЛИТЕРАТУРЫ}

1. Вавилова А.Ю., Летчиков А.В., Соколова М.А. Эконометрическая модель рейтинговой оценки регионов Приволжского федерального округа на основе социально-экономического потенциала // Вестн. Удм. ун-та. Сер. Экономика и право. 2006, № 2. С. 31-43.

2. Удмуртия в цифрах.2017 год: (стат. ежегод.): (№ 003 по кат.) / Федер. служба гос. статистики, Территор. орган Федер. службы гос. статистики по Удмурт. Респ.; [редкол.: Е.А.Данилов и др.]. Ижевск: Удмуртстат, 2018. $349 \mathrm{c}$

3. Удмуртия в цифрах. 2011 год: (стат. сб.): (№003 по кат.) / Федер. служба гос. статистики, Территор. орган Федер. службы гос. статистики по Удмурт. Респ.; [редкол.: Е.А.Данилов и др.]. Ижевск: Удмуртстат, 2012. 326 с.

4. Сайт Федеральной службы государственной статистики. URL: http://www.gks.ru/

5. Экономическая безопасность России. Общий курс: [учебник] / В.К. Сенчагов, Б.В. Губин, В.И. Павлов [и др.], РАН, Ин-т экономики, Центр финанс. - банк. исслед., РА-ЕН, Секция «Проблемы макроэкономики и соц. рыночного хоз - ва»; под ред. В.К. Сенчагова. М.: Дело, 2005.

6. Мухин А.А. Применение методов математического моделирования в оценке факторных зависимостей индексов (Worldwide governance indicators) государственного управления // Вестн. Удм. ун-та. Сер. Экономика и право. 2014. Вып. 2. С. 53-60.

7. Мухин А.А. Применение методов статистического моделирования в оценке факторных зависимостей численности населения Российской Федерации // Вестн. Удм. ун-та. Сер. Экономика и право. 2016. Т. 26, вып. 3. C. 29-39.

8. Мухин А.А. Непараметрические методы обнаружения взаимосвязей макроэкономических показателей в Российской Федерации // Вестн. Удм. ун-та. Сер. Экономика и право. 2015. Т. 25, вып. 6. С. 42-50.

9. Ожидаемый рост ВРП Удмуртии // Сайт газеты «Коммерсантъ. Удмуртия». URL: https://www.kommersant.ru/ doc/3968656 (дата обращения: 08.01.2020).

Мухин Алексей Арьевич, кандидат юридических наук, доцент ФГБОУ ВО «Удмуртский государственный университет» 426034, Россия, г. Ижевск, ул. Университетская, 1 (корп. 4) E-mail: ualex@udm.ru 


\section{A.A. Mukhin}

\section{FORECASTING THE VALUES OF ECONOMIC GROWTH FACTORS IN A REGION (A CASE OF THE UDMURT REPUBLIC)}

DOI: $10.35634 / 2412-9593-2020-30-1-78-83$

The article deals with forecasting the values of economic growth factors in a region on the example of the Udmurt Republic. A statistically significant multiple linear regression equation (that explains the dynamics of the gross regional product from the signs-factors) is derived, a factorial forecast is developed and the results obtained are interpreted. Deflation method has been applied to eliminate the impact of price growth and GRP value has been calculated in 2007 prices. On the basis of multiple regression analysis, a matrix of paired correlation coefficients is calculated and informative factors of the model are selected. The significance of paired correlation coefficients is checked. The model is constructed in its natural form with informative factors only. The statistical significance of the regression coefficients is evaluated with the help of the Student's $t$-criterion, the quality of the equation is estimated through the average approximation error, which confirm the sufficiently high quality of the model. The predicted value of the result is calculated. It was found that if the current trends in the dynamics of these factors persist, we can expect the growth of real (physical volume) GRP over the period $2016-2020$ by $26 \%$ or $5.5 \%$ annually, which meets the requirements of economic security of the region. The above information can be used to develop programs of regional economic development and design in the system of state and municipal administration.

Keywords: forecasting the values of factors of economic growth of a region, endogenous, exogenous variables, correlation, regression analysis of factors, estimation of quality of the regression equation by means of Fisher's F-criterion, significance of coefficients of regression by means of Student's t-criterion, quality of the equation through an average error of approximation, calculation of the forecast value of economic growth of the Udmurt Republic.

Received 10.01.2020

Mukhin A.A., Candidate of Law, Associate Professor

Udmurt State University

Universitetskaya st., 1/4, Izhevsk, Russia, 426034

E-mail: ualex@udm.ru 